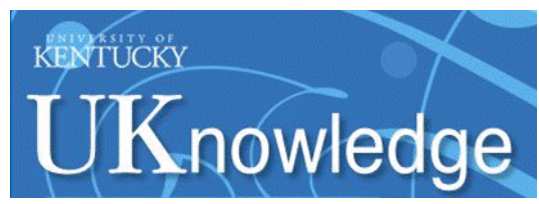

University of Kentucky

UKnowledge

\title{
"It's Just a Way of Fitting In:" Tobacco Use and the Lived Experience of Lesbian, Gay, and Bisexual Appalachians
}

\author{
Keisa Bennett \\ University of Kentucky, keisa.bennett@uky.edu \\ JaNelle M. Ricks \\ Emory University \\ Britteny M. Howell \\ britteny.howell@uky.edu
}

Follow this and additional works at: https://uknowledge.uky.edu/familymedicine_facpub

Part of the Medicine and Health Sciences Commons

Right click to open a feedback form in a new tab to let us know how this document benefits you.

\section{Repository Citation}

Bennett, Keisa; Ricks, JaNelle M.; and Howell, Britteny M., "'It's Just a Way of Fitting In:" Tobacco Use and the Lived Experience of Lesbian, Gay, and Bisexual Appalachians" (2014). Family and Community Medicine Faculty Publications. 2.

https://uknowledge.uky.edu/familymedicine_facpub/2

This Article is brought to you for free and open access by the Family and Community Medicine at UKnowledge. It has been accepted for inclusion in Family and Community Medicine Faculty Publications by an authorized administrator of UKnowledge. For more information, please contact UKnowledge@lsv.uky.edu. 
"It's Just a Way of Fitting In:" Tobacco Use and the Lived Experience of Lesbian, Gay, and Bisexual Appalachians

Digital Object Identifier (DOI)

http://dx.doi.org/10.1353/hpu.2014.0186

Notes/Citation Information

Published in The Journal of Health Care for the Poor and Underserved, v. 25, no. 4, p. 1646-1666.

Copyright ( $\odot 2014$ The Johns Hopkins University Press. This article first appeared in The Journal of Health Care for the Poor and Underserved, Volume 25, Issue 4, Nov., 2014, pages 1646-1666. 


\title{
"It's Just a Way of Fitting In:" Tobacco Use and the Lived Experience of Lesbian, Gay, and Bisexual Appalachians
}

\author{
Keisa Bennett, MD, MPH \\ JaNelle M. Ricks, DrPH \\ Britteny M. Howell, MA, ABD
}

\begin{abstract}
Lesbian, gay, and bisexual (LGB) people are affected by multiple health disparities and risk factors, including tobacco use. Few studies to date have examined tobacco use specifically in rural LGB populations, and none has investigated the intersections of identity, rural LGB culture, and tobacco. The purpose of this study was to explore the perspective of Appalachian LGB people regarding tobacco use. Methods. Nineteen LGB-identified Appalachian residents participated in audiotaped, semi-structured interviews. Two authors analyzed and coded transcripts through constant comparison, and determined themes through consensus. Results. Five themes emerged: the convergence of Appalachian and LGB identities, tacit awareness of LGB identity by others, culture and tobacco use, perceived associations with tobacco use, and health beliefs and health care. Conclusions. LGB Appalachians connect stress and culture to tobacco, but seem less aware that partial concealment of their identity might be a source of the stress that could influence their smoking.
\end{abstract}

Key words: Tobacco, sexual minorities, rural, qualitative.

Arowing body of research has identified health disparities that negatively affect

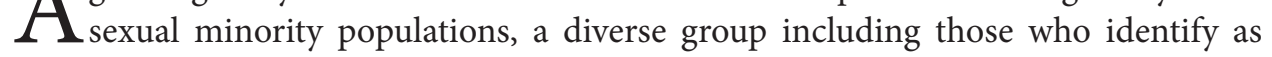
lesbian, gay, and bisexual ${ }^{*}(\text { LGB. })^{*}$ Lesbian, gay, or bisexual identity is a risk factor for drug and alcohol abuse, ${ }^{1-3}$ and stress and depressive symptoms, ${ }^{4}$ especially within communities having lower numbers of same-sex couples. ${ }^{5}$ Additionally, LGB persons

\footnotetext{
**The acronym LGB is used throughout this paper interchangeably with the term, "sexual minority" and is meant to encompass the diverse spectrum of non-heterosexual identity. Although gender minorities, generally referred to as transgender-spectrum, are also thought to live with similar health disparities, the research on that population is nascent and we were not able to recruit transgender participants to this study.

KESIA BENNETT is associated with the Department of Family and Community Medicine, University of Kentucky, Lexington KY. JANELLE RICKS is associated with the Department of Behavioral Sciences and Health Education, Rollins School of Public Health, Emory University, Atlanta GA. BRITTENY HOWELL is associated with the Department of Anthropology and Behavioral Science, University of Kentucky, Lexington KY. Keisa Bennett is the corresponding author and can be reached at K302 Kentucky Clinic, 740 S Limestone, Lexington KY 40508. Or by email at keisa.bennett@uky.edu.
} 
may have an increased prevalence of chronic and debilitating diseases, ${ }^{6}$ including cardiovascular disease $\mathrm{e}^{7,8}$ and cancer. ${ }^{9}$

Health status and the impact of sexual orientation on health vary as a function of myriad contextual factors, including community of residence. ${ }^{10}$ Differences in sexual minority health status are especially noticeable when comparing urban and rural regions: of interest is the rural Appalachian region, a 205,000-square-mile area along the mountains from southern New York to northern Mississippi, where $42 \%$ of the population is rural (compared with $20 \%$ of the national population). ${ }^{11}$ Living in Appalachia is itself an independent risk factor for a number of health conditions such as cancer and heart disease ${ }^{12-14}$ Therefore, LGB Appalachian residents are doubly at risk for unfavorable health disparities.

Tobacco use is a risk behavior that strongly affects both Appalachians and LGB persons. Smoking prevalence in Appalachia is nearly double the national average ${ }^{15}$ and rural populations are disproportionately affected by smoking-attributable disease and death. ${ }^{16}$ Potential contributing factors include low socioeconomic status (SES), lack of cessation services, lower levels of education, inadequate insurance coverage, and distance to health care facilities. ${ }^{17-19}$ Various studies conducted in urban settings have demonstrated high rates of smoking among sexual minority populations in the United States. ${ }^{3,620,21}$ Smoking prevalence among rural LGB persons is not well established but at least two studies provide evidence that in some areas the proportion of current smokers among LGBT in a rural state or rural areas of a state $(45-46 \%)^{22,23}$ exceeds even the general Appalachian rate (34\%), ${ }^{15}$ though no studies offer direct comparisons. Given the paucity of population-based surveys that include questions about sexual orientation, the actual patterns of smoking and tobacco use among rural sexual minorities remain unknown.

Differences between tobacco use among rural and urban populations overall are likely rooted in culture, socioeconomic disparities, and differences in health care resources. ${ }^{19,24}$ It is unclear what factors might underlie potential differences in tobacco use between rural and urban LGB populations. There is evidence that minority stress, social isolation, smoking culture of LGB bars (historically the safest spaces for community gathering), and targeted tobacco marketing, contribute to disproportionate LGB smoking. ${ }^{20,25,26}$ Although psychosocial predictors of risk-taking behavior such as low sense of belonging and high perception of stigma do influence health behavior of rural LGB individuals, ${ }^{27}$ some Appalachian sexual minorities likely cultivate resiliency by forming more diffuse and diverse social networks, a common experience for LGB people in general. ${ }^{28-30}$ Heightened tobacco use among Appalachian LGB persons therefore, might additionally be related to unique factors stemming from local culture and geography.

The few quantitative studies documenting high rates of smoking in rural LGBT samples did not explore reasons underlying this disparity or protective factors against $\mathrm{it}^{22,23}$ leaving a gap in which they suggest that targeted interventions with regard to prevention and cessation may be necessary. However, there is not enough understanding of rural LGBT tobacco use to design interventions or more comprehensive quantitative studies. Given the lack of research in this area, we took an exploratory approach to understanding tobacco use and beliefs among a segment of rural sexual minority people 
in a particularly high-risk region to take in a sample of perspectives that can inform quantitative methods and research in other areas. We aimed to explore qualitatively the perspective of Appalachian LGB people regarding tobacco use in their geographic and social communities. The primary research question was, "What are Appalachian LGB persons' perspectives on tobacco use in relationship to their lived identity as sexual minorities?" Through the analysis of perspectives of LGB Appalachian smokers and nonsmokers, we demonstrate the ways in which Appalachian and LGB identities interact and how they converge with stressors and social relationships to produce patterns and beliefs concerning tobacco use. We identify the veiled visibility, or tacit but not outright recognition of LGB status, as a factor relating these identities to the minority stress that may contribute to smoking behavior.

\section{Methods}

Participants. Study participants were recruited in the Appalachian region of Eastern Kentucky from Kentucky Area Development District (ADD) 9-13. ${ }^{31}$ We chose the ADD designations because they exclude some counties that border urban counties although they are generally considered Appalachian. The proximity of these border counties may closely resemble the experience of living in an urban area in terms of access to the LGB community and resources. Inclusion criteria also included being at least 18 years of age and self-identifying as lesbian, gay, bisexual, or transgender. None of the recruited participants identified as transgender, therefore the sample is referred to as LGB throughout the paper. Both tobacco users and non-users were recruited in an effort to understand both protective and risk factors for tobacco initiation, cessation, and patterns of use. Because of the qualitative and exploratory nature of this study, we conceived of risk of smoking in the most general sense, encompassing initiation, heaviness of smoking, contexts related to smoking, and cessation. We asked specific question prompts about initiation and cessation but in our analysis encompassed any risk of smoking as defined by the participants.

Recruitment of socially or geographically isolated research participants is challenging; in this case there were no established local community organizations or gathering places in which to directly recruit. In an effort to maximize number and diversity of participants, we used a multimodal strategy. Recruitment occurred through study flyers posted at research, clinical, and educational practice sites and disseminated through listservs targeting LGB and ally (LGB supportive) students at local colleges and universities. Nine participants were recruited through direct request or snowball sampling from a sexual health project targeting rural men who have sex with men. Additionally, participation was invited through a project website disseminated through the flyers and advertising on social networking sites, and an advertisement in a newsletter widely read by sexual minorities across Kentucky. Participants signed written consent forms were paid $\$ 25$ for completing the interview. This protocol was reviewed and approved by the University Institutional Review Board.

Participants provided demographic data through an online form separate from their interview. Data requested included age, gender (choices included female, male, transgender MTF, transgender FTM, intersex, genderqueer, questioning, other), sexual 


\section{Table 1.}

\section{PARTICIPANT DEMOGRAPHICS ${ }^{\mathrm{a}}$}

\begin{tabular}{lcc}
\hline \hline & $\#$ & $\%$ \\
\hline Female gender & & \\
Race & 4 & 22.2 \\
$\quad$ White & 17 & 94.4 \\
$\quad$ Biracial & 1 & 3.6 \\
Sexual orientation & & \\
$\quad$ Gay or lesbian & 17 & 94.4 \\
$\quad$ Bisexual & 1 & 3.6 \\
Education & 2 & 11.1 \\
$\quad$ High school/GED & 10 & 55.6 \\
$\quad$ Some college & 4 & 22.2 \\
$\quad$ 4 year college degree & 2 & 11.1 \\
$\quad$ Post-graduate/professional & & \\
\hline aAmong the 18 participants completing demographic data. \\
bo participants identified a gender other than male or female. \\
\hline
\end{tabular}

identity or orientation (choices included straight, gay, lesbian, bisexual, queer, questioning, other), ethnicity (U.S. Census categories), ${ }^{32}$ education, county of birth and current residence, smoking status, and tobacco products used. In order adequately to protect confidentiality of study subjects who might be identifiable if paired with demographic data, we did not associate the demographic data with the interview transcripts; therefore the quantitative description of the sample is presented in aggregate. Of the 19 individuals interviewed, one did not provide demographic data and was excluded from the quantitative description of participants; however, this person's interview was transcribed and qualitatively analyzed. Detailed demographic data appear in Table 1. Participants ranged in age from 20 to 53 (with 11 in their 20s) and lived in 10 different counties. Seven of the 19 resided in the same county. Based on a single question asking for the best description of how much they smoked (presenting two levels of daily smoking, two levels of nondaily smoking, four durations of having quit, and "I have never smoked"), 10 participants were defined as smokers, seven were non-smokers, and one participant omitted a response. Table 2 lists participant tobacco use characteristics.

Although we did not transfer each subject's smoking status to his/her transcript, the authors labeled each interviewee as a current, social, former, or never smoker based on self-disclosure within the interview itself for purposes of identifying the possible bias toward or against tobacco of each participant. These labels may or may not match the self-identifications and behaviorally-based categories presented in Table 2. Social smokers were considered to be those who reported within the transcript nondaily but yet repeated smoking. Former smokers were those describing having quit smoking for a duration lasting at least several months. Because our analysis did not reveal major 


\section{Table 2.}

\section{DISTRIBUTION OF TOBACCO USE ${ }^{\mathrm{a}}$}

\begin{tabular}{|c|c|c|c|}
\hline $\begin{array}{l}\text { Would you say } \\
\text { you're a smoker? }\end{array}$ & $\begin{array}{l}\text { Amount smoked } \\
\text { in packs per day }\end{array}$ & Prior use & Other tobacco use $\mathrm{u}^{\mathrm{b}}$ \\
\hline \multirow[t]{3}{*}{ Yes $=10^{c}$} & $\geq 1 / 2 \mathrm{ppd}=5$ & & $\begin{array}{l}\text { e-cigarette }=1 \\
\text { none } / \text { no answer }=4\end{array}$ \\
\hline & $<1 / 2 \operatorname{ppd}=5$ & & $\begin{array}{l}\text { Hookah = } 1 \\
\text { e-cigarette = } 1 \\
\text { cigars }=1 \\
\text { none }=2\end{array}$ \\
\hline & $\begin{array}{l}\text { (occasional } \\
\text { assumed) }=1\end{array}$ & Quit $\leq 6$ mo $=1$ & e-cigarette $=1$ \\
\hline \multirow[t]{3}{*}{$\mathrm{No}=7$} & $\mathrm{n} / \mathrm{a}$ & Quit 6 mo to 2 yrs $=1$ & E-cigarette $=1$ \\
\hline & & Quit $\geq 2$ yrs $=2$ & $\begin{array}{l}\text { Chew/dip }(\text { Twist })=1 \\
\text { None }=1\end{array}$ \\
\hline & & Never $=4$ & $\begin{array}{l}\text { Chew/dip }=1 \\
\text { Hookah }=1 \\
\text { None }=2\end{array}$ \\
\hline
\end{tabular}

differences in codes or themes among smokers, social smokers, former smokers, and nonsmokers, we organized our results by theme rather than smoking label.

Research procedures and measures. Semi-structured interviews lasting approximately 25 to 100 minutes each were audio-taped and professionally transcribed. The first author conducted 12 interviews and another member of the research team conducted the remaining seven. Interviews were conducted in such a way that participants were given sufficient opportunity to say all that he or she could about each item of interest. Some participants elaborated greatly on their answers and others provided shorter responses. The interview guide was created based on literature review and discussions with subject matter experts. Interview topics included participants' sense of identity, perceptions of local culture and LGB social networks, impressions of smoking prevalence, and how social contacts influence smoking (see Box 1).

Analysis. The first and second authors conducted and analyzed the first eleven transcripts using a grounded theory-inspired approach. ${ }^{33}$ Contrary to classical grounded theory, we came with a priori questions based on a thorough literature review; however, we employed open-ended questioning to allow themes to come organically from the study participants themselves. ${ }^{34}$ We analyzed interviews using the constant comparative method, comparing each interview transcript with previous transcripts, searching for repetitive themes when they appeared across interviews as well as new themes, and 


\section{Box 1.}

QUESTIONS INCLUDED IN THE INTERVIEW GUIDE FOR SEMI-STRUCTURED PILOT INTERVIEWS. NOTE THAT THE QUESTION GUIDE INCLUDED INTRODUCTORY AND TRANSITIONAL STATEMENTS AS WELL AS PROMPTS TO PROBE LESS DETAILED ANSWERS FURTHER.

\section{Disclosure}

How would you describe your level of being "out" in terms of your friends, family, and work or school knowing your LGBT identity?

Tobacco/Smoking

Would you say that you're a smoker?

Do you think that here in this area, smoking is more common with LGBT people than with straight people?

For those who smoke any amount currently: Why do you think you started smoking? Have you tried to stop? Why haven't you tried or been able to quit?

For those who are nonsmokers: Why do you think you did not ever start smoking? Have you ever felt pressured to start; if so, how? Why do you think most people you know who smoke don't quit?

\section{Health Priorities and Health Care}

Are there other health issues that are more common or more of a problem for you personally? What about for other LGBT people here?

Where do you usually go for healthcare?

\section{Social Networks}

Can you describe, in general, the groups

of people you know? (examples of demographic categories listed)

Would these answers be different for your acquaintances or the people you spend time with at work or school?

Which kinds of people in your life do you go to for advice or support?

Which people do you find yourself helping out or advising?

Do you have LGBT friends or acquaintances in your hometown or home county?

How did you find these friends?

What would you do to find friends if you moved to another county?

Do you have a significant other?

If so: how did you meet?

If not: how would you find someone to date?

Do you travel out of your home county to spend time with friends?

How important is the Internet in your life?

\section{Summary}

What are the good things about being an LGBT (use term person identifies for themselves) person living in an Appalachian county?

Do you have any anything else you would like us to know or any questions about this study? 
refining our interview questions and process based on thematic patterns. ${ }^{35}$ We began with open coding, attempting to assign all of the participants' remarks to a substantive concept. Twice during the initial analysis, we met to reconcile coding units and redefine the codebook and began more selective and conceptual coding of sections relevant to the established and emerging patterns of codes and themes. ${ }^{34}$ After all interviews were complete we met a third time to reconcile differences and construct a final codebook. The inter-rater reliability (IRR) was satisfactory at 0.72 . This final codebook was used to code or recode all transcripts. All three authors discussed and created a list of themes emerging from the coding of all the transcripts.

\section{Results}

Because of the rapidly changing cultural norms and legal rights concerning LGB persons, we felt that historical studies were not adequate to determine a priori the main themes related to LGB identity for these participants; therefore we began the interviews also exploring the question: "How is LGB identity lived and expressed in Appalachia?" As a background to our exploration of tobacco use and identity, we discovered two relevant identity themes: convergence of Appalachian and LGB identity and tacit awareness of LGB identity by others. Convergence is used here to mean the way in which different elements of identity interact to produce a sense of self and place in the world that is distinct from either individual element and is more than the sum of the parts. Tacit awareness is the phrase we are using to refer to the degree to which the LGB element of identity is known without it being explicitly confirmed.

Convergence of Appalachian and LGB identity. All participants explicitly or implicitly identified themselves as both sexual minority and Appalachian, though they often used terms other than rural or Appalachian, for example, “... I also identify as a mountain person, as a mountain boy..." More commonly, rural affiliation was expressed as part of multiple identities, for example, "Gay, country, city-lover, smoker, drinker." (smoker) They expressed a sense of community and family being inherent in rural life, a factor clearly connecting most of them with place. For example, one participant said,

This is the town I grew up in and the county I grew up in and so these are people who have known me since I was 10, 11, 12 and so ... even when I left they were always my core group of folks because we've known each other for so long and we've dealt with so much stuff together. (social smoker)

Another expressed a sentiment of advocacy tying him to his rural roots:

I want to make a change in the gay community in the state of Kentucky; I don't know but I just feel like I've got this urge that I want to make a change, I want to be remembered for something and if it means that I can come to a small town and open up and maybe start a group or something... (smoker)

Nevertheless, social isolation associated with being a rural LGB person was a subtheme of this discussion. One person expounded on this experience: "Well I feel on an island all by myself most of the time. It's not something that I'm aware of that many people 
around me ... identify in my group." (former smoker) Another participant expressed well the sentiment of internal struggle to escape isolation but retain family and cultural roots:

Then on top of it, identity crisis; who am I, you know am I gay or not gay ... out or not, do I want to stay here or leave because that's always a big pull with mountain people; we have this, we have this really pull-tug relationship with the mountains. We have to be here but we hate being here; like it's constantly at us. This sense of displacement that we feel that this is our home but we don't really feel at home here... (social smoker)

Participants related that stigma and discrimination were still active issues in their lives. Many expressed the struggle to reconcile their families' religious values with their orientation; for example; "And then my grandmother's religion is kind of like conflicting with her like, she loves me but then her religion is like dictating that she shouldn't [accept anything associated with homosexuality] type of mentality." (non-smoker) Another participant related the common experience of seemingly well-intentioned family members wanting to help an by changing sexual orientation, saying, “... well the exact words from my mother were, if you're gay, we're going to have to go talk to the preacher and have you fixed, have you sent away and fixed." (smoker) Religiously-fueled stigma seemed to extend beyond a barrier to family support, functioning to inhibit community support as well. One participant discussed discrimination with regard to the lack of community-based LGB resources:

When you come from the Bible belt and I always call my hometown like part of the buckle of the Bible belt, ... like there's nowhere to talk about it; there's no help, there's no outreach program, there's no youth center where you can talk about it and it's like this tradition of passing on from generation to generation this prejudice against gay people.(nonsmoker)

The same participant noted that homogeneity of people in rural areas makes them ill equipped to handle diversity:

... It was a great place to grow up until you realize who you are and then it's a really hard place to stay because people there are so used to being like a homogenous type of society that when there is a difference, it's really hard to deal with it because again, people don't have the tools. (nonsmoker)

Participants did recognize an evolution of LGB visibility and inclusion in Appalachia. One stated, "From the 18-40 year old group, I rarely meet someone who's like blatantly homophobic and I feel like most people know somebody that's gay." (smoker) Another participant corroborated this: "I've been trying to take my friends with me ... and it's not been the easiest but they're all very open-minded so it's been a lot smoother than I think the journey with my family will be." (nonsmoker) Others tempered their sense of progress with a clear assumption that discrimination was still very real; for example:

You know everybody talks about how awful it is as far as discrimination and I'm sure it is, but it's not, it's nothing like it used to be. You know I don't, you don't get yelled 
at; you don't get beat up. Of course most of the women I know, lesbians especially, they all carry, we all carry guns; we have to. (nonsmoker)

Tacit awareness of LGB identity by others. Because LGB identity is not inherently visible, the primary strategy for most LGB people to maintain a sense of safety is through controlling when, where, and how they are "out" (i.e., identity known) versus being "in the closet," (i.e., identity concealed). In general, study participants were out to family, friends, and co-workers, though the majority identified at least one person, group, or setting in which they were either still "in the closet" or in a "don't ask, don't tell" situation. Being in the closet was less common but clearly situational. One participant described being out to everyone, but then appeared uncomfortable in the setting in which the interview was taking place and expressed minor concerns that someone from work would happen to hear the conversation. She stated:

Like on [college] campus, the environment is, you are who you are, you do what you want. But like where I'm [training in the work setting], I'm not out; I'm not, I mean there are certain people that... I can trust them through conversations and things to come out but like I don't just walk up to somebody and be like, hi, I'm a lesbian. (smoker)

A system of veiled visibility in which people were known to be LGB but no verbal acknowledgement about sexuality was made, appeared to be particularly common. Comments related to this subtheme were mentioned by almost every participant, revealing a cultural norm in the way sexual identity is implicitly handled in interactions between sexual minority persons and those in the majority. Many participants mentioned that they avoided using any identifying words around a grandparent, co-worker, or health care provider while also assuming that the person already knew. One related his veiled visibility to respect for his neighbors' religion, stating, "I have no problem with telling anybody except for like in our little town home community they, our neighbor ladies, they're very Christian like so we can't tell them or anything but I think they have an idea." (smoker) One participant succinctly summarized, “... it's just, it's kind of like the topic that you don't talk about; it's the elephant in the room; everybody sees it, we just don't talk about it." (smoker) Another stated, "But my parents knew; again, it's one of those things where I feel like the mentality back home is, if we don't talk about it, then it doesn't have to be real." (nonsmoker)

Even when participants were truly out, they often felt a need to moderate certain aspects of themselves to smooth social interactions, for example, "... when it comes to like my father and my sister and around my nieces and nephews, you know I try to pull back from some of the mannerisms and conversations and, you know, things that I say." (smoker) Similarly, a number of younger participants mentioned avoiding any LGB identity labels, references, or pictures on social networking sites commonly accessed by heterosexual relatives and peers. They described implicit rules well understood by their peers concerning what kinds of posts were appropriate for various social networking platforms. For example, they knew never to post anything overtly LGBT related or even politically controversial on Facebook because multiple family members, including grandparents, would see it. The participants discussing social media all commented on 
avoiding exposing those family members to any overt LGBT references. They could, however, use Twitter fairly freely due to the absence of older or more conservative family members on that network.

Despite having to hide, avoid discussing, or moderate expression of their identities, almost all participants identified benefits of being LGB, even in a rural area. A few expressed ideas about being better able to relate to and accept other minorities, as well as having the support of a chosen gay community. A number related the sense of personal growth they associated with having survived, or even thrived, as someone different. One participant described this resiliency particularly well:

I think you have a greater appreciation for being gay because you have to fight for it around here. Like you don't just get up and be gay; you've gotta make people respect that ... you've gotta be like, you know what, no you're not going to mistreat me, you're not going to discriminate me, you're not going to make me be somebody I'm not. I'm gay; if you can't deal with it, then get the hell over it or get out. Like and I think it makes you stronger. (nonsmoker)

Perspectives on tobacco use in relationship to lived identities. Three themes emerged related to the primary research question of the intersection of tobacco use and lived sexual minority identity: culture and tobacco use, perceived associations with tobacco use, and health beliefs and health care.

Culture and tobacco use. Most participants perceived a strong Appalachian tobacco culture, stating or implying that individual use was rampant and that support for controls on smoking was low. One participant described the integration of tobacco into families through generations, saying:

I mean her sister smoked, brother smoked, everybody smoked and one right after another and so it was you know almost as though it was just bred right into them and that's what they were supposed to do in a way. Even though they knew that it was bad, it was still, well everybody smokes, you know, so. (nonsmoker)

In contrast, most of the participants did not perceive a higher smoking prevalence among LGB people, at least not over and above that of the rural population in general. When asked about specific smoking behavior, however, the majority reported smoking with LGB friends or knowing fewer straight (non-LGB) smokers than LGB smokers. Many also acknowledged that the smoking prevalence could be higher among LGB, for example, "Those high rates are probably higher in LGBTQ just because LGBTQ folks have to also deal with the fact that they're LGBTQ on top of being all of, you know just living in a completely oppressed and depressed place." (nonsmoker)

Perceived associations with tobacco use. Three subthemes emerged under this theme: social implications, stress (with an emphasis on minority stress), and "fitting in." Although all denied any specific peer pressure to use tobacco, participants expressed a strong sense of social associations with smoking. Most expressed ambivalence to the question of whether that association was specific to their LGB community or general culture. One person identified the universal influence of peer norms even in the absence of peer pressure: 
... so there's like five people in a group ... and four people go out to smoke; you're not just going to sit in a room so you're going to go out too and then most of the time you'll smoke too or you'll just kind of stand there but most people aren't just going to stand there either. (smoker)

Even a couple of the those who considered themselves nonsmokers or at least did not smoke enough to ever buy their own cigarettes, admitted to smoking on at least a weekly basis and always with specific friends at a bar or restaurant. One said,

Well I tend to smoke if I'm extremely stressed and ... if I've been drinking but I don't smoke other than that. And so it's usually just for social stuff so ... if I happen to be stressed that day ... I'll just have a cigarette but it's usually just one.... And usually I only smoke with other gay people; that's interesting ... (social smoker)

Participants also referenced smoking cessation barriers in the context of social norms. They predominantly implicated (explicitly or implicitly) the high overall prevalence of tobacco use in the region as the central barrier to prevention, followed by the mental association of smoking with gathering places. The statement of one participant who had tried to quit a number of times epitomized this theme:

But the only way I was doing that [not smoking] is between jobs; if I was off work between jobs, looking for another job and I was at home and not out around everybody, I could stand it at the house but the moment I would start back working or ... hanging out with my friends again ... having the money to go out ... and socialize with them and being around them smoking, I would automatically pick back up smoking. (smoker)

Even in light of these strong social norms, stress was by far the most discussed influence on smoking behavior and failure to quit. Most participants felt that general Appalachian norms (i.e., predominately normalized smoking behavior) and stressors rather than anything specific to LGB status predominantly drove smoking behaviors in their communities. One participant whose own mother had started smoking in mid-life epitomized this view with his theory:

And when you have to work that hard to make money that doesn't match, you know, the labor you're putting out, it adds a level of stress and the easiest way to deal with that stress is to go and have a beer or to go and, you know, light up on a smoke break or whatever and get that momentary release from all the stress that you have going on. (nonsmoker)

Smoking related to LGB identity as a form of "minority stress," or the additional stress associated with stigma, also highly contributed to this theme. Some felt that LGB-related stressors added to the difficulties of working class Appalachia; one pointed out likely associations with staying closeted, saying, “. . . ones that are still closeted and they, like in a workplace they stress ... Because they're trying to keep their personal life separate so it might make them stress more or smoke more." (smoker) In contrast, another participant cited the stress that occurs for those who are visible as LGB: 
If we're out in public, they holler names they shouldn't holler. More peer pressure. . . More straight people yell, call you names; it puts a little bit of pressure on you, makes you feel like you shouldn't be in public sometimes... It makes you want to smoke. (smoker)

As is evident in the above quotations, stigma-related stress was intimately related to the subtheme of "fitting in," to Appalachian or local culture rather than LGB culture. One participant cited the high overall prevalence of smoking in saying, "And so it's one more way for them to fit in, into the general norm of the world." (nonsmoker) In general, participants thought that smoking was a way for people to claim belonging or assert acceptable gender expression in a culture in which they were otherwise considered aberrant. One, for example, cited the need for gay men to project a specific body type: "I know a lot of gay men that I know smoke to lose weight because there's this whole like beauty myth dynamic in the gay male world of being like thin or fit..." (nonsmoker) Another noticed that both gay men and lesbian women seemed to use cigarettes to express their own type of masculinity:

It's a trying to fit into the norm because more of the straight general world smokes. . . In this region at least ... and as long as you're not (emphasis added) holding it like a French cigarette ... kind of like a lady if you're a guy. Or a lot of the lesbians hold them like, you know just like men so they look more masculine. . You know masculine rather than feminine so it's odd. But I think that's what it is; it's just a way of fitting in. (nonsmoker)

Health beliefs and health care. We identified two subthemes under this theme: skepticism and fatalism, and lack of engagement with health care. Participants expressed skepticism about both LGB smoking as a problem and the impact of tobacco on health. As mentioned above, when asked whether LGB rural residents use tobacco more than other rural residents, the participants' predominant response was that regional smoking prevalence is so high that LGB smoking just couldn't be much higher. All participants also knew a multitude of smokers and several referenced at least one who had smoked without obvious ill effect into advanced age or a young person who had died of lung disease unrelated to smoking. Multiple participants also expressed various forms of fatalism related to smoking, ranging from low self-efficacy to quit to the community sense of saturation with anti-smoking messages that had failed to notably produce changes, for example:

... there's been a lot of groups in east Kentucky that always talk to us about smoking and there's always this smoking thing in east Kentucky and everyone smokes here... I think that you know as I said, so much of it also is like this social cultural thing that I don't know how you combat. (social smoker)

Lack of engagement with health care also seemed to play a role in smoking cessation. A number of participants identified lack of health insurance as a barrier to treatment and there was minimal mention of pharmacological cessation aids. None reported ever using a program such as a support group, counseling, or hypnosis. When asked how 
most quitters they knew had been successful, they overwhelmingly cited people who had quit completely on their own, for example: "But for the most people who I know who have quit, they had to because of health reasons that they, if they didn't smoke, they was going to die and they quit cold turkey, just quit."(social smoker) The lack of medical assistance might be a symptom of a larger problem with health care access and utilization. A few had trusted primary care providers (PCPs), but all described finding this PCP as a fortunate coincidence; they had not received any prior information indicating the PCP was competent in LGB patient care. None thought there was any reliable way to find such a person. Most expressed reluctance by the LGB community to come out to health care providers and none had been directly asked about sexual identity by a provider. No participant directly connected the lack of such services (e.g., LGB welcoming mental health care) to smoking; however, one person again emphasized the added minority stress on the LGB population:

I think that we're already not starting at a good place around here in terms of mental health and I think that to add having a different sexuality to it, it doesn't help. And nevertheless it, I mean, I definitely think for the gender nonconforming folks, for like trans folks ... I definitely know for sure in that world, yes in this area, those folks are highly, highly depressed. (social smoker)

\section{Discussion}

Nineteen LGB-identified Eastern Kentuckians, both smokers and non-smokers, provided rich and complex perceptions and experiences at the intersection of their identities as rural and LGB people and the convergence of those identities with their beliefs about tobacco and its use locally. Encompassing both background exploration of modern lived identity as well as perspectives on Appalachian LGB tobacco use, five themes emerged: the convergence of Appalachian and LGB identities, tacit awareness of LGB identity by others, culture and tobacco use, perceived associations with tobacco use, and health beliefs and health care. The convergence of identities theme is consistent with the literature on rural LGB individuals and demonstrates the tension experienced by those who feel strong ties with their Appalachian roots and culture despite the lack of a strong local LGB community. For example, Annes and Redlin interviewed 30 gay men who felt "compelled" to migrate to cities during the development of their gay identity, but later found that they did not recognize themselves in the expectations and norms of urban culture and subsequently returned to areas more compatible with their rural values despite having access to fewer LGB-related resources. ${ }^{36}$ A number of qualitative studies have documented that LGB people who choose to live in rural areas place a higher value on having a more relaxed pace of life, being closer to nature, and living near family. ${ }^{37-39}$

The participants' perception of a continued strong local LGB-related stigma was also consistent with the established literature. Eastern Kentucky is part of a Bible Belt state in which voters have passed a constitutional amendment banning same-sex marriage. ${ }^{40}$ As Lindhorst reported, religiosity can predispose residents to forms of homophobia. ${ }^{41}$ The link between religion and homophobia relates to participants' frequent mention 
of perceived conflict with religious values when discussing lack of social and health care resources specifically targeting LGB persons. In a more recent survey of LGB in Wyoming, a majority of respondents reported having experienced harassment and victimization, with personal and institutional discrimination being higher for women in rural areas than those in urban areas. ${ }^{42}$ One analysis of a rural Kentucky sample reflected the presence and evolution of stigma as mentioned by several participants. Eldridge et al. found that heterosexual students exhibited many prejudices against LGB people, but also found some evidence that these students might own more tolerant perceptions than previous generations. ${ }^{43}$ Perception of a slowly evolving acceptance of LGB in rural areas, especially among young people, is consistent with findings in urban areas, where "gay neighborhoods" are becoming less segregated from the rest of the city and are more diverse. ${ }^{44}$

Although the subtheme of the evolving acceptance of rural LGB people was evident, few people in this study used orientation labels liberally, and some even expressed concern for those people in their communities who did so. This phenomenon, here called tacit awareness, or veiled visibility, was described over and over again by our respondents. This terminology suggests that they are accepted by community members with the tacit understanding that their sexual identity is not acknowledged verbally or in any overt way (e.g., social network posts, bumper stickers) that forces others to confront it directly. Describing the experiences of gay men in a rural Western state, Boulden also noted that his participants avoided any public displays of affection and wanted to avoid "hitting [their neighbors] in the face with it." Despite describing themselves as "very open" and rural life as more relaxed, the men also spoke about being constantly on guard and trying not to appear effeminate in order to ensure safety. ${ }^{37}$ In another study of gay men living in a rural area containing neighborhoods with a reputation for acceptance, the participants still reported that public displays of affection were "pushing the envelope" in certain areas. ${ }^{38}$ Taken together, our data and the recent literature suggest that "outness" in rural areas may have progressed in recent decades from a stark difference between being in or out of the closet, to this veiled visibility in which LGB people presume or even know for sure that their friends and family are aware, but they do not declare their identities publicly. The stress of concealment has documented evidence for associations with poor health outcomes including mental health ${ }^{45-47}$, physical health ${ }^{48}$ and even CD4 count and viral load in those living with HIV. $^{49,50}$ Recent studies, however, have revealed that the relationship between orientation disclosure and health is not consistent across demographic groups. McGarrity et al. found that disclosure was associated with better physical health and health care utilization measures in men with high socioeconomic status (SES) but actually predicted health problems for low SES men. ${ }^{48}$ Similarly, Fekete et al. found that nonHispanic White men who had disclosed their HIV status to their mothers and had high family support had better CD4 counts and viral loads, while Latino men with lower family support had worse CD4 and viral loads when they had disclosed their status to their mothers. ${ }^{51}$ These studies suggest that cultural and economic factors mediate the relationship of outness and health, and lend credence to the need to understand varying degrees of outness, particularly in the rural Appalachian setting in which SES tends to be low $^{52}$ and cultural factors play a large role in social norms. Most studies, 
however, have measured outness in just a few Likert scale questions (e.g., "Rate how out you are to your friends, with ' 1 ' meaning not out at all to ' 5 ' meaning completely out."). This approach does not capture tacit awareness, outness through social media, or other qualitative differences in how people manage LGB identities. Our finding of the predominant theme of tacit awareness emphasizes the need for a more nuanced approach to measuring outness versus concealment in health research.

Related to concealment, the subtheme of minority stress seems most to connect themes of lived and social identity with themes related to tobacco use. According to Meyer (2003), sexual minorities may experience minority stress because they are a social group subject to stigma and prejudice, which predisposes them to excess stress. The minority stress theory posits that this excess stress leads to adverse health behaviors, outcomes, and ultimately explains some health disparities. ${ }^{4}$ Minority stress is often assumed to be at work in health disparities among multiple minority groups and is now being tested systematically. ${ }^{53}$

As mentioned above, limited studies on rural LGBT samples support higher smoking rates among rural LGB individuals compared with their urban peers. ${ }^{22,23,54}$ None, however, sought to elucidate associations to minority stress that might be more prominent for sexual minorities in the rural setting. The participants in our study endorsed their own assumption of minority stress, noting both stressors they experienced as sexual minorities in Appalachia and the predominant role that stress played in smoking behaviors, though many did not perceive that tobacco use was higher among LGB persons than the general population. The pressure to fit in with societal norms certainly is consistent with studies of the general population, ${ }^{55,56}$ but sure to be heightened in populations who are already out of the norm.

The reason participants would endorse the reality of additional minority stress but not perceive higher proportions of tobacco use in fellow LGB persons is difficult to discern. Perception of LGB smoking rates may be entangled with the perception of very high smoking prevalence in the general local community. This study was designed to assess community perceptions of Appalachian LGBT smoking prevalence, not to measure smoking rates in this population; it certainly may be true that actual rates are not higher than the general Appalachian prevalence. Conversely, the proportion of LGB smokers may be higher, but the perception is that the region is so saturated with smoking behavior that additional stress could not further increase smoking prevalence. Another explanation might lie in the participants' general failure to perceive veiled visibility or tacit awareness as an endorsed stressor (i.e., when endorsed, minority stress was often implied in reference to those who were fully closeted or out but openly harassed or shunned). Behaviors commonly described by participants such as screening their health care providers for acceptance, moderating any stereotypical characteristics around family members, and filtering social media discussions based on who had access to a particular network clearly impose stress in excess of that experienced by the general local population. Several participants also discussed the relationship of smoking to masculinity perceptions. The role of smoking in promoting a more masculine image has been previously documented. ${ }^{57}$ At least one study has also demonstrated that male gender is protective for mental health and psychosocial well-being in rural areas regardless of sexual orientation, ${ }^{58}$ suggesting that projecting a masculine identity may 
have particular advantages in rural settings (for both gay men and lesbians). Although these examples of managing identity seemed much more pervasive and common than being fully closeted or experiencing outright discrimination, the participants' lack of connection between those behaviors and their own stress might also help to explain their ambivalence about smoking prevalence in the local LGB community.

The importance of minority stress is highlighted by the growing body of evidence that it contributes to decrements in mental and physical health. ${ }^{59}$ Current literature supports reduction of minority stress through the promotion of social connection among community members. ${ }^{59-61}$ Meanwhile, Appalachian and other rural LGB people are at especially high risk of social isolation (for an example see $\mathrm{Gray}^{62}$ ), as well as internalized homophobia, ${ }^{28,37}$ giving efforts to connect them to identity-affirming communities potentially greater effect. It is plausible that organizational, policy-related, and provider-related interventions to increase community-building and social capital for rural LGB could positively affect LGB-related minority stress and provide health behavior benefits. Organization-level interventions include formation of new community organizations, connection of existing programs to rural areas, re-training of local service providers, and using technology to enhance communications and create virtual gathering spaces. Evidence from policy-related interventions demonstrates effectiveness in changing social norms and community health. The tobacco control movement provides an excellent example of how public health interventions such as smoking bans lead not only to changes in community norms ${ }^{63}$ but also objective reductions in individual and community morbidity. ${ }^{64}$ There is an absence of literature on the effects of policy-related interventions such as local fairness ordinances, incentives for LGBfriendly businesses, and protections for public meeting spaces in rural communities, making this topic deserving of further research. Understanding and addressing social norms such as perceptions of discrimination, stress levels, and health of LGB people may improve program efficacy. Interventions to increase sexual minority patients' use of primary care and reduce the stress associated with accessing health care include education for health care providers on LGB health issues, as well as incentives to promote an LGB competent and welcoming atmosphere in health care offices and hospitals. Such interventions to improve culturally appropriate health care would address a current barrier that likely influences sexual minorities' access to tobacco cessation treatment.

Limitations of this study include those common to qualitative research. Interviewee responses cannot be generalized to represent all rural or Appalachian LGB persons. Additionally, the nature of our recruitment efforts resulted in participants who were predominantly male and in which one county of residence was over-represented. As in all research involving purposive sampling of hard-to-reach populations, those who participated are also assumed to be more open and vocal about their LGB identity and related opinions than those who remain more closeted. We used multiple, varied recruitment methods, interviewed participants in a place of their choosing, and did not connect their demographic data to their interview transcript in an attempt to minimize this limitation. Interviewing those people who are the most out of the closet in their communities likely represents a best-case-scenario in terms of social connectivity and mental health, meaning subthemes such as minority stress could actually be underrepresented. Additionally, we did not ask specific questions about activities such as 
alcohol use that are commonly associated with smoking in the general literature. ${ }^{65}$ Although we expected the association with alcohol to be named by the majority of participants, it was not mentioned enough to become a theme and we chose to structure our results and discussion according to the issues raised by the participants rather than according to our expectations. The strengths of the study include rich and nuanced data on identity, stress and tobacco use that has never been qualitatively studied in a sample of rural sexual minorities. In addition, interviews with both smokers and nonsmokers and people from a variety of ages and educational levels provided rich and diverse information on Appalachian LGB perceptions concerning tobacco use.

Conclusion. Lesbian, gay, and bisexual Appalachians still struggle with identityformation and even the most "out" of them operate in system of veiled visibility of their sexual identities. They express high levels of stress related to both the general rural environment and their lived identities within it. They connect tobacco smoking to both stress and existing social structures, but seem less aware that managing their veiled visibility is likely a major source of the stress that could influence smoking within the rural LGB community. Efforts to increase culturally competent and safe mental health care and tobacco cessation services are potential avenues to reduce individual and group smoking. Public health measures such as smoke-free ordinances aimed at changing community norms would also affect rural LGB people. In addition, many rural LGB could be influenced by targeted messaging and events in the urban places to which they travel.

\section{Acknowledgments}

Dr. Nancy Schoenberg, Dr. Karen Roper, and Ms. Catherine Hardin were indispensable in manuscript submission. Mr. Tom Collins served as an interviewer. This study was funded by a grant from National Center for Advancing Translation Sciences, National Institutes of Health (no. KL2TR000116.)

\section{References}

1. Diamant AL, Wold C, Spritzer K, et al. Health behaviors, health status, and access to and use of health care: a population-based study of lesbian, bisexual, and heterosexual women. Arch Fam Med. 2000 Nov-Dec;9(10):1043-51. http://dx.doi.org/10.1001 /archfami.9.10.1043

2. McCabe SE, Bostwick WB, Hughes Tl, et al. The relationship between discrimination and substance use disorders among lesbian, gay, and bisexual adults in the United States. Am J Public Health. 2010 Oct;100(10):1946-52. Epub 2010 Jan 14. http:// dx.doi.org/10.2105/AJPH.2009.163147

3. Skinner WF, Otis MD. Drug and Alcohol Use Among Lesbian and Gay People in a Southern U.S. Sample. J Homosex. 1996;30(3):59-92. http://dx.doi.org/10.1300 /J082v30n03_04

4. Meyer IH. Prejudice, social stress, and mental health in lesbian, gay, and bisexual populations: conceptual issues and research evidence. Psych Bull. 2003 Sep;129(5): 674-97. http://dx.doi.org/10.1037/0033-2909.129.5.674

5. Hatzenbuehler ML, Keyes KM, McLaughlin KA. The protective effects of social/ 
contextual factors on psychiatric morbidity in LGB populations. Int J Epidemiol. 2011 Aug;40(4):1071-80. Epub 2011 Feb 17. http://dx.doi.org/10.1093/ije/dyr019

6. Conron KJ, Mimiaga MJ, Landers SJ. A population-based study of sexual orientation identity and gender differences in adult health. Am J Public Health. 2010 Oct;100(10): 1953-60. Epub 2010 Jun 1. http://dx.doi.org/10.2105/AJPH.2009.174169

7. Case P, Austin SB, Hunter DJ, et al. Sexual orientation, health risk factors, and physical functioning in the Nurses' Health Study II. J Womens Health (Larchmt). 2004 Nov; 13(9):1033-47. http://dx.doi.org/10.1089/jwh.2004.13.1033

8. Hatzenbuehler ML, McLaughlin KA, Slopen N. Sexual orientation disparities in cardiovascular biomarkers among young adults. Am J Prev Med. 2013 Jun;44(6): 612-21. http://dx.doi.org/10.1016/j.amepre.2013.01.027

9. Brown JP, Tracy JK. Lesbians and cancer: an overlooked health disparity. Cancer Causes Control. 2008 Dec;19(10):1009-20. Epub 2008 Jun 13. http://dx.doi.org/10.1007 /s10552-008-9176-Z

10. Institute of Medicine. The health of lesbian, gay, bisexual, and transgender people: building a foundation for better understanding. Washington, DC: National Academies Press, 2011.

11. Appalachian Regional Commission. Population Estimates 2009. Washington, DC: Appalachian Regional Commission, 2009. Available at: http://www.arc.gov/reports /custom_report.asp?REPORT_ID=40.

12. Agency for Healthcare Research and Quality. National Health Disparities Report 2012. Rockville, MD: United States Department of Health and Human Services, 2013.

13. Bennett KJ, Olatosi B, Probst JC. Health disparities: a rural-urban chartbook. Columbia, SC: South Carolina Rural Health Research Center, 2008.

14. Halverson JA, Ma L, Harner EJ. An analysis of disparities in health status and access to health care in the Appalachian Region 2004. Washington, DC: Office of Social Environmental \& Health Resources, 2004.

15. Stoops WJ, Dallery J, Fields NM, et al. An internet-based abstinence reinforcement smoking cessation intervention in rural smokers. Drug Alcohol Depend. 2009 Nov 1;105(1-2):56-62. Epub 2009 Jul 16. http://dx.doi.org/10.1016/j.drugalcdep.2009 .06 .010

16. Rahilly C, Farwell W. Prevalence of smoking in the United States: A focus on age, sex, ethnicity, and geographic patterns. Cardiovasc Risk Reports. 2007;1(5):379-83. http://dx.doi.org/10.1007/s12170-007-0062-0

17. Vital signs: Current cigarette smoking among adults aged $\geq 18$ years-United States, 2009. MMWR Morb Mortal Wkly Rep. 2010 Sep 10;59(35):1135-40.

18. Harris JK, Geremakis C, Moreland-Russell S, et al. Demographic and geographic differences in exposure to secondhand smoke in Missouri workplaces, 2007-2008. Prev Chronic Dis. 2011 Nov;8(6):A135. Epub 2011 Oct 17.

19. Hutcheson TD, Greiner KA, Ellerbeck EF, et al. Understanding smoking cessation in rural communities. J Rural Health. 2008 Spring;24(2):116-24. http://dx.doi.org /10.1111/j.1748-0361.2008.00147.x

20. Lee JGL, Griffin GK, Melvin CL. Tobacco use among sexual minorities in the USA, 1987 to May 2007: a systematic review. Tob Control. 2009 Aug;18(4):275-82. Epub 2009 Feb 10. http://dx.doi.org/10.1136/tc.2008.028241

21. Ryan H, Wortley PM, Easton A, et al. Smoking among lesbians, gays, and bisexuals: a review of the literature. Am J Prev Med. 2001 Aug;21(2):142-9. http://dx.doi.org /10.1016/S0749-3797(01)00331-2 
22. Bennett K, McElroy JA, Johnson AO, et al. A persistent disparity: smoking in rural sexual and gender minorities. LGBT Health. 2014; In Press.

23. Lee JGL, Goldstein AO, Ranney LM, et al. High Tobacco Use among Lesbian, Gay, and Bisexual Populations in West Virginian Bars and Community Festivals. Int J Environ Res Public Health. 2011 Jul;8(7):2758-69. Epub 2011 Jul 1. http://dx.doi.org /10.3390/ijerph8072758

24. Ricketts TC. Rural Health in the United States. New York, NY: Oxford University Press, 1999.

25. Blosnich J, Lee JG, Horn K. A systematic review of the aetiology of tobacco disparities for sexual minorities. Tob Control. 2013 Mar;22(2):66-73. Epub 2011 Dec 14. http:// dx.doi.org/10.1136/tobaccocontrol-2011-050181

26. Trocki KF, Drabble LA, Midanik LT. Tobacco, marijuana, and sensation seeking: comparisons across gay, lesbian, bisexual, and heterosexual groups. Psychol Addict Behav. 2009 Dec;23(4):620-31. http://dx.doi.org/10.1037/a0017334

27. King M, Semlyen J, Tai SS, et al. A systematic review of mental disorder, suicide, and deliberate self harm in lesbian, gay and bisexual people. BMC Psychiatry. 2008 Aug 18;8:70. http://dx.doi.org/10.1186/1471-244X-8-70

28. Cohn RJ, Hastings SL. Resilience among rural lesbian youth. J Lesbian Stud. 2010; 14(1):71-9. http://dx.doi.org/10.1080/10894160903060325

29. Meyer IH. The right comparisons in testing the minority stress hypothesis: comment on Savin-Williams, Cohen, Joyner, and Rieger (2010). Arch Sex Behav. 2010 Dec; 39(6):1217-9. http://dx.doi.org/10.1007/s10508-010-9670-8

30. Riggle EDB, Rostosky SS. A Positive View of LGBTQ. Lanham, MD: Rowman \& Littlefield, 2012.

31. Kentucky Council of Area Development Districts. About ADDs. Frankfort, KY: Kentucky Council of Area Development Districts, 2012. Available at: http://www.kcadd .org/overview/.

32. United States Census Bureau. Race. Washington, DC: United States Census Bureau, 2013. Available at: https://www.census.gov/topics/population/race/about.html.

33. Glaser B. Basics of Grounded Theory Analysis. Mill Valley, CA: Sociology Press, 1992.

34. Grounded Theory Institute. What Is Grounded Theory? Mill Valley, CA: Grounded Theory Institute, 2008. Available at: http://www.groundedtheory.com/what-is-gt.aspx.

35. Owen WF. Interpretive themes in relational communication. Quart J Speech. 1984; 70:274-87. http://dx.doi.org/10.1080/00335638409383697

36. Annes A, Redlin M. Coming out and coming back: Rural gay migration and the city. J Rural Studies. 2012;28(1):56-68. http://dx.doi.org/10.1016/j.jrurstud.2011.08.005

37. Boulden WT. Gay Men Living in a Rural Environment. J Gay Lesb Soc Serv. 2001; 12(3-4):63-75. http://dx.doi.org/10.1300/J041v12n03_05

38. Kirkey K, Forsyth A. Men in the valley: gay male life on the suburban-rural fringe. J Rural Stud. 2001;17(4):421-41. http://dx.doi.org/10.1016/S0743-0167(01)00007-9

39. Smith DP, Holt L. 'Lesbian migrants in the gentrified valley' and 'other' geographies of rural gentrification. J Rural Stud. 2005;21(3):313-22. http://dx.doi.org/10.1016 /j.jrurstud.2005.04.002

40. Legislative Research Commission. Consitution of the commonwealth of Kentucky: information bulletin No. 59. Frankfort, KY: Legislative Research Commission, 2013.

41. Lindhorst T. Lesbians and gay men in the country. J Gay Lesbian Soc Serv. 1998;7(3): 1-11. http://dx.doi.org/10.1300/J041v07n03_01 
42. Leedy G, Connolly C. Out in the cowboy state. J Gay Lesbian Soc Serv. 2008;19(1): 17-34. http://dx.doi.org/10.1300/J041v19n01_02

43. Eldridge VL, Mack L, Swank E. Explaining comfort with homosexuality in rural America. J Homosex. 2006;51(2):39-56. http://dx.doi.org/10.1300/J082v51n02_03

44. Spring A. Declining Segregation of Same-Sex Partners: Evidence from Census 2000 and 2010. Popul Res Policy Rev. 2013 Oct 1;32(5). http://dx.doi.org/10.1007 /s11113-013-9280-y

45. Beals KP, Peplau LA, Gable SL. Stigma management and well-being: the role of perceived social support, emotional processing, and suppression. Pers Soc Psychol Bull. 2009 Jul;35(7):867-79. Epub 2009 Apr 29. http://dx.doi.org/10.1177 /0146167209334783

46. Juster RP, Smith NG, Ouellet E, et al. Sexual orientation and disclosure in relation to psychiatric symptoms, diurnal cortisol, and allostatic load. Psychosom Med. 2013 Feb; 75(2):103-16. Epub 2012 Jan 29. http://dx.doi.org/10.1097/PSY.0b013e3182826881

47. Morris JF, Waldo CR, Rothblum ED. A model of predictors and outcomes of outness among lesbian and bisexual women. Am J Orthopsychiatry. 2001 Jan;71(1):61-71. http://dx.doi.org/10.1037/0002-9432.71.1.61

48. McGarrity LA, Huebner DM. Is being out about sexual orientation uniformly healthy? The moderating role of socioeconomic status in a prospective study of gay and bisexual men. Ann Behav Med. 2014 Feb;47(1):28-38. http://dx.doi.org/10.1007 /s12160-013-9575-6

49. Cole SW, Kemeny ME, Taylor SE, et al. Accelerated course of human immunodeficiency virus infection in gay men who conceal their homosexual identity. Psychosom Med. 1996 May-Jun;58(3):219-31. http://dx.doi.org/10.1097/00006842-199605000 $-00005$

50. Ullrich PM, Lutgendorf SK, Stapleton JT. Concealment of homosexual identity, social support and CD4 cell count among HIV-seropositive gay men. J Psychosom Res. 2003 Mar;54(3):205-12. http://dx.doi.org/10.1016/S0022-3999(02)00481-6

51. Fekete EM, Antoni MH, Lopez CR, et al. Men's serostatus disclosure to parents: associations among social support, ethnicity, and disease status in men living with HIV. Brain Behav Immun. 2009 Jul;23(5):693-9. Epub 2009 Jan 21. http://dx.doi.org /10.1016/j.bbi.2009.01.007

52. Partridge MD, Betz MR, Lobao L. Natural resource curse and poverty in Appalachian America. Am J Agr Econ. 2013 Jan 1;95(2):449-56. http://dx.doi.org/10.1093/ajae /aas086

53. Kuyper L, Fokkema T. Minority stress and mental health among Dutch LGBs: examination of differences between sex and sexual orientation. J Couns Psychol. 2011 Apr; 58(2):222-33. http://dx.doi.org/10.1037/a0022688

54. Fisher CM, Irwin JA, Coleman JD. LGBT Health in the Midlands: A Rural/Urban Comparison of Basic Health Indicators. J Homosex. 2014;61(8):1062-90. http://dx.doi .org/10.1080/00918369.2014.872487

55. Christakis NA, Fowler JH. The collective dynamics of smoking in a large social network. N Engl J Med. 2008 May 22;358(21):2249-58. http://dx.doi.org/10.1056 /NEJMsa0706154

56. Lakon CM, Hipp JR, Timberlake DS. The social context of adolescent smoking: a systems perspective. Am J Public Health. 2010 Jul;100(7):1218-28. Epub 2010 May 13. http://dx.doi.org/10.2105/AJPH.2009.167973 
57. Panchankis JE, Dougherty LR, Westmaas JL. The influence of sexual orientation and masculinity on young men's tobacco smoking. J Consult Clin Psychol. 2011 Apr;79(2): 142-52. http://dx.doi.org/10.1037/a0022917

58. Galliher VE, Rostosky SS, Hughes HK. School belonging, self-esteem, and depressive symptoms in adolescents: an examination of sex, sexual attraction status, and urbanicity. J Youth Adolesc. 2004;33(3):235-45. http://dx.doi.org/10.1023 /B:JOYO.0000025322.11510.9d

59. Frost DM, Lehavot K, Meyer IH. Minority stress and physical health among sexual minority individuals. J Behav Med. 2013 Jul 18. [Epub ahead of print] http://dx.doi .org/10.1007/s10865-013-9523-8

60. Herrick AL, Stall R, Chmiel JS, et al. It gets better: resolution of internalized homophobia overtime and associations with positive health outcomes among MSM. AIDS Behav. 2013 May;17(4):1423-30. http://dx.doi.org/10.1007/s10461-012-0392-x

61. Kertzner RM, Meyer IH, Frost DM, et al. Social and psychological well-being in lesbians, gay men, and bisexuals: the effects of race, gender, age, and sexual identity. Am J Orthopsychiatry. 2009 Oct;79(4):500-10. http://dx.doi.org/10.1037/a0016848

62. Gray M. Out in the country: youth, media, and queer visibility in rural America. New York, NY: New York University Press, 2009.

63. Cheng KW, Okechukwu CA, McMillen R, et al. Association between clean indoor air laws and voluntary smokefree rules in homes and cars. Tob Control. 2013 Oct 10. [Epub ahead of print] http://dx.doi.org/10.1136/tobaccocontrol-2013-051121

64. Wilson LM, Avila Tang E, Chander G, et al. Impact of tobacco control interventions on smoking initiation, cessation, and prevalence: a systematic review. J Environ Public Health. 2012;2012:961724. Epub 2012 Jun 7.

65. De Leon J, Rendon DM, Baca-Garcia E, et al. Association between smoking and alcohol use in the general population: stable and unstable odds ratios across two years in two different countries. Alcohol Alcohol. 2007 May-Jun;42(3):252-7. http://dx.doi .org/10.1093/alcalc/agm029 